\title{
Telaah Actor Network Theory dalam Kajian Sistem Pangan
}

\author{
Bunga Pertiwi Tontowi Puteri ${ }^{{ }^{*}}$
}

${ }^{1}$ Universitas Indonesia, Indonesia

\author{
A R T I C L E I N F O \\ Article history: \\ Received 12 July 2021 \\ Accepted 03 November \\ 2021 \\ Available online 01 \\ December 2021 \\ Kata Kunci: \\ Sistem Pangan; Actor \\ Network Theory; \\ Pendekatan Jaringan; \\ Sosiologi \\ Keywords: \\ Food System; Actor \\ Network Theory, Network \\ Approach, Sociology
}

\begin{abstract}
A B S T R A K
Tujuan dari artikel ini adalah menelaah sejauh mana penggunaan Actor Network Theory dalam kajian sistem pangan. Fokus penelitian kajian sistem pangan dalam sosiologi mengalami perkembangan, salah satunya Actor Network Theory yang memiliki paradigma jaringan. Actor Network Theory dinilai dapat menggali kompleksitas dari sistem pangan dengan tawaran gagasannya yang dinilai cukup radikal bagi sosiologi. Metode yang digunakan adalah studi literatur dengan sumber utama berupa 12 artikel jurnal ilmiah tentang sistem pangan yang menggunakan analisis Actor Network Theory selama kurun waktu 5 tahun. Hasil telaah menunjukkan terdapat dua titik fokus pembahasan yang berbeda dalam kajian-kajian yang ada yaitu dinamika sistem pangan dan eksplorasi produk pangan, selain itu ditemukan potensi pengembangan kajian sistem pangan dengan pendekatan Actor Network Theory ke isu yang lebih luas seperti konsep agensi, keadilan pangan, keamanan pangan dan gerakan sosial.
\end{abstract}

\section{A B S T R A C T}

The purpose of this article is to examine the extent to which Actor-Network Theory is used in the study of food systems. The focus of research on food system studies in sociology has developed, one of which is the Actor-Network Theory, a network paradigm. Actor-Network Theory is considered to explore the complexity of the food system by offering ideas that are considered quite radical for sociology. The method is a literature study with the primary source in 12 scientific journal articles about the food system using Actor-Network Theory analysis over five years. The study results show that there are two different focus points of discussion in the existing studies, namely the dynamics of the food system and the exploration of food products. In addition, it is found to develop food system studies using the ActorNetwork Theory approach to broader issues such as the concept of agency, food justice, food safety, and social movements.

\footnotetext{
* Corresponding author.

E-mail addresses: bunga.pertiwi91@ui.ac.id
} 


\section{Pendahuluan}

Makanan yang berada di meja makan kita memiliki perjalanan yang panjang dan kompleks. Makanan bukan hanya tentang nutrisi yang dikandungnya, namun juga unsur sosial yang melingkupi makanan tersebut. Kompleksitas dari sebuah makanan tidak hanya berdampak bagi produsen dan konsumen, namun juga masyarakat dan negara. Makanan perlu dipandang lebih luas sebagai sebuah entitas sosial, politik dan ekonomi, yang termanifestasi dalam sistem pangan yang berkembang secara historis. Sistem pangan di setiap negara tidak bisa begitu saja dilepaskan dari konteks sistem pangan global. Sejarah menunjukkan perkembangan sistem pangan diawali dari restrukturisasi pertanian skala besar pada tahun 1930 di Eropa Barat dan Amerika Utara, mendorong liberalisme perdagangan dan produksi pangan secara transnasional (Tilzey, 2019). Sehingga permasalahan dan dinamika dalam sistem pangan menjadi lebih kompleks.

Kehadiran sistem pangan yang kompleks ini mendorong berbagai disiplin ilmu sosial untuk membedah sistem pangan dari sudut pandang sosial, tidak terkecuali Sosiologi. Pembahasan sistem pangan dalam Sosiologi berpusat pada jejaring mulai dari manusia, organisasi, wilayah, peraturan, ekosistem, nilai/kepercayaan yang saling terikat dan menjadi latar-belakang keberadaan pangan, untuk menggambarkan segala proses yang menghubungkan petani dengan konsumen. Caloran (2012) menguraikan tiga pertanyaan sosiologis terhadap kajian sistem pangan: 1) Apa penyebab dari keadaan sistem pangan yang terjadi sekarang ini, kenapa ketidakadilan dan pemborosan dibiarkan bertahan?; 2) Apa "solusi" yang diusulkan dan apakah solusi tersebut menguatkan atau melemahkan status quo yang ada dalam sistem pangan?; 3) Siapa yang diuntungkan dan siapa yang dirugikan ketika sebuah masalah dalam sistem pangan diatasi?

Terdapat berbagai perkembangan fokus kajian sistem pangan dalam sosiologi untuk menjawab pertanyaan sosiologis diatas, diantaranya kajian sistem pangan berfokus pada ekonomi-politik (Bernstein, 2016; Duncan \& Pascucci, 2017; Dwiartama \& Rosin, 2014; Leblond \& Trottier, 2016), kelembagaan (Bui et al., 2019; Challies, 2012), kultur (Jenatton \& Morales, 2020; Mak, 2014), ekologi (Dixon \& Richards, 2016; Lamine, 2015; Plumecocq et al., 2018) dan perkembangan paradigma sistem atau jaringan (Dwiartama, 2014; Lamine, 2015), serta lainnya. Dari perkembangan kajian sistem pangan dalam sosiologi tersebut, paradigma jaringan merupakan pendekatan yang dinilai dapat menggambarkan bentuk dari sistem pangan yang beragam dan kompleks dengan lebih komprehensif.

Adalah Actor Network Theory (ANT) suatu pendekatan jaringan atau sistem yang digunakan untuk mengkaji sistem pangan. Pada awalnya ANT merupakan pendekatan yang lahir dari kajian Science and Technology pada sekitar akhir tahun 70-an dan awal tahun 80-an. Penekanan ANT dalam Science and Technology adalah bahwa unsur "sosial" memiliki peran dalam menciptakan artefak teknis - sistem atau jaringan. Pada sekitar tahun 90-an, ANT kemudian berkembang dalam disiplin ilmu sosial-humaniora, dengan salah satu tokohnya adalah Bruno Latour dan Michel Callon. Dalam disiplin sosiologi, ANT awalnya sering digunakan dalam kajian Sosiologi Ilmu Pengetahuan yang berfokus pada inovasi dan kemajuan ilmu pengetahuan, kemudian berkembang ke berbagai fokus kajian sosiologi lainnya (Farahzad \& Varmazyari, 2018).

ANT merupakan salah satu pengkritik radikal terhadap gagasan substansial ilmu sosial konvensional. Perhatian ilmu sosial konvensional mendasarkan analisisnya pada dikotomi alammasyarakat, manusia-non manusia, subjek-objek, mikro-makro serta struktur-agensi, bagi ANT dikotomi ini kaku dan tidak mampu menganalisis fenomena alam dan sosial serta persilangannya secara mendalam dan luas (Fox \& Alldred, 2018; Nimmo, 2011; Tang et al., 2018). Pendekatan ANT mencoba mengatasi hal ini melalui paradigma jaringan.

Inti dari ANT adalah pemahaman bahwa jaringan aktor merupakan pencapaian yang harus dijelaskan dari pada diasumsikan (Baiocchi et al., 2013). ANT memiliki sifat jaringan aktor berbeda secara ontologis dengan jaringan lainnya. Aktor - atau aktan dalam terminologi ANT bukanlah sekedar nodes dalam jaringan; akan tetapi para aktor juga melahirkan tindakan melalui interaksi antar mereka di dalam jaringan (Indongesit Williams, 2020). Jaringan merupakan tindakan yang dihasilkan oleh interaksi para aktor, dan aktor merupakan entitas 
yang kemunculannya juga dihasilkan oleh interaksi. ANT mendefinisikan aktor sebagai hasil dari jaringan material heterogen yang saling berinteraksi (Dwiartama, 2014), sebuah entitas hibrida (Nimmo, 2011). Dikarenakan ke-aktor-an bukanlah hal eksklusif dan melekat pada sebuah entitas, maka dimungkinkan non-manusia menjadi aktor akibat aktivitas-aktivitas relasional.

ANT membantu memahami tindakan atau cara-cara yang dilakukan oleh objek - yang tampaknya pasif terhadap manusia - dalam membentuk subjektivitas serta tindakan (Baiocchi et al., 2013). ANT menempatkan "elemen alam", "elemen sosial", "elemen manusia" dan "elemen non-manusia" sebagai aktor setara yang terhubung dan dibentuk melalui proses knowledge translation, sehingga membentuk sistem jaringan yang heterogen melalui interaksi secara bertahap (Tang et al., 2018). Gagasan-gagasan ANT tersebut dinilai bermanfaat untuk mengkaji sistem pangan yang di dalamnya terdapat berbagai entitas manusia, non-manusia, alam dan sosial. Entitas tersebut saling berinteraksi dan mempengaruhi dinamika sistem pangan. David Goodman merupakan salah satu tokoh awal yang membawa pendekatan ANT ke dalam kajian pangan sosiologi.

Stoddard dan Cantor (2017) menjelaskan telah berkembang banyak kajian sistem pangan yang menggunakan ANT sebagai alat analisis selama beberapa dekade. Hal ini karena ANT memungkinkan peneliti sistem pangan untuk menggali produksi hingga konsumsi dalam satu waktu dengan mengkonseptualisasikan sistem pangan sebagai jaringan manusia, hewan, virus, pengetahuan, peraturan, wacana dan lainnya. Penggunaan ANT juga digunakan untuk memahami determinan dan efek dari produksi dan konsumsi secara simetris (Le Velly \& Dufeu, 2016). Selain itu melalui ANT peneliti sistem pangan dapat mengikuti para aktor/aktan untuk memahami bagaimana mereka terdaftar dalam jaringan, serta bagaimana hubungan dalam jaringan dipertahankan. Analisis yang ditawarkan ANT memberikan perangkat untuk menjawab pertanyaan sosiologis terhadap sistem pangan

Berbagai penelitian dan kajian sistem pangan menggunakan ANT telah banyak dilakukan. Perlu dilakukannya studi pustaka untuk mendeteksi sejauh mana ANT dimanfaatkan dalam kajian sistem pangan. Sebuah kajian perlu dipetakan sehingga perkembangan khasanah keilmuan dapat terus tumbuh. Pemetaan literatur akan membantu untuk merumuskan kebaruan dari fokus perihal yang diteliti. Sejauh ini masih belum ada artikel atau penelitian yang secara fokus membahas perkembangan kajian sistem pangan-pendekatan ANT. Sedangkan pemetaan kajian sistem pangan menggunakan ANT penting untuk mengidentifikasi bagaimana ANT digunakan dan sejauh mana ANT dimanfaatkan, sehingga dapat mengidentifikasi potensipotensi apa yang dapat dikembangkan baik bagi ANT maupun kajian sistem pangan.

\section{Metode}

Sumber utama studi pustaka ini adalah artikel jurnal bereputasi internasional mengenai sistem pangan yang menggunakan analisis atau pendekatan ANT dalam kurun waktu lima tahun terakhir (Januari 2016 - Februari 2021). Pengambilan sumber literatur dilakukan melalui website Scopus pada tanggal 25 Februari 2021. Pencarian artikel jurnal pada website Scopus menggunakan kata kunci "actor network theory" dan "food system". Dilakukan pembatasan melalui menu 'Refine Results' dengan pencarian artikel terbatas pada: publikasi bersifat final, jenis dokumen adalah artikel jurnal, subjek area berupa social-science, dan artikel berbahasa inggris. Hasil pencarian mendapatkan 20 artikel, akan tetapi 8 artikel tidak digunakan karena tidak berbahasa inggris, tidak menggunakan ANT dan/atau tidak membahas mengenai sistem pangan. Sehingga total 12 artikel digunakan sebagai sumber utama artikel ini.

\section{Hasil dan Pembahasan}

\section{Kajian sistem pangan dengan ANT: Sistem pangan dan produk pangan}

Dua belas artikel jurnal yang dijadikan sumber utama artikel ini seluruhnya membahas isu sistem pangan, baik di salah satu bagian dari sistem pangan atau sistem pangan secara menyeluruh. Seluruh artikel ini menggunakan ANT sebagai teori dan/atau pendekatan yang digunakan, dan terdapat beberapa artikel yang menggabungkan ANT dengan teori lain. Pada tahun 2016 ditemukan tiga kajian yang membahas sistem pangan menggunakan ANT. Pertama 
adalah kajian yang dilakukan oleh Le Velly dan Dufeu (2016) dengan tujuan menggali hibriditas dari jaringan pangan alternatif di Prancis, dalam artikel ini mereka menggunakan konsep hybrid collectives dari ANT dan Market Agencement yang gagasannya juga dipengaruhi oleh ANT. Kedua, kajian Powell (2016) yang mencoba mengeksplorasi bagaimana jenis jagung putih tertentu di Portugal diubah menjadi varietas unggul bernama Pigarro melalui jenis percobaan pemuliaan tanaman partisipatif dimana tatanan sosial berperan dalam produksi dan reproduksi Pigarro. Analisis Powel seluruhnya menggunakan pendekatan dan konsep ANT seperti ontologi datar, analisis aktor non-manusia dan translation. Ketiga, Kristensen dan Kjeldsen (2016) mengkaji proyek Pig City yang mengusulkan penggabungan produksi daging babi, tomat dan energi untuk merefleksikan visi masa depan sistem pangan pertanian. Kajian ini menggunakan pendekatan ANT dan pembahasan yang lebih mendalam pada gagasan Studi Sains dan Teknologi.

Di tahun 2017 terdapat dua artikel jurnal, pertama adalah kajian Stoddard dan Cantor (2017) yang bertujuan melakukan penilaian kerentanan jaringan sistem pangan babi dengan menganalisis bagaimana hubungan manusia dan non-manusia menciptakan dan menstabilkan paparan wabah penyakit mulut dan kaki pada jaringan industri pangan babi di California. Kajian ini menggabungkan konsep translation dari ANT, yang lebih berfokus pada proses enrolment, dengan Root-ed Network Framework. Kajian kedua adalah De Hoop dan Jehlicka (2017) tentang keterlibatan aktivis Lembaga Swadaya Masyarakat Lingkungan Ceko dalam Food SelfProvisioning (FSP) yang dilihat melalui diskursus dan praktik sistem pangan dari FSP, yang kemudian dianalisis menggunakan ANT.

Pada tahun 2018 juga ditemukan dua artikel, sedangkan pada tahun 2019 tidak ditemukan artikel yang sesuai dengan kriteria. Artikel pertama di tahun 2018 adalah kajian yang dilakukan oleh Tang dkk (2018). Kajian ini bertujuan mengkaji pembangunan nilai merek (brand) pangan lokal berdasarkan kerangka kerja sistem pangan lokal dan ANT, dengan melakukan pemetaan persepsi aktor-jaringan. Proses translation dari ANT digunakan sebagai alat analisis. Kedua, di tahun 2018 diterbitkan kajian De Castro dan Torres-Albero (2018) tentang bagaimana kualitas berbeda dari seedless table grape dibangun melalui prosedur kontrol kualitas yang mencoba menstabilkan hubungan antara aktor manusia dan non-manusia. Konsep ANT yang digunakan dalam kajian ini adalah framing dan overflowing.

Kajian Sistem Pangan menggunakan ANT paling banyak ditemukan pada tahun 2020 dengan jumlah empat buah kajian. Pertama kajian Farhangi dkk (2020), bertujuan menganalisis hambatan yang dihadapi dalam pengembangan High-tech Urban Agriculture (praktek produksi pangan alternatif) untuk kemudian diintegrasikan ke proses perencanaan kota. Kajian ini menggunakan konsep ANT seperti translation, ontologi datar dan simetri umum, yang digabungkan dengan multi-level perspective (MLP) on sustainability. Kedua kajian Kopczynska (2020), mencoba menguji potensi keberlanjutan dari jaringan pangan lokal dengan membandingkan jaringan pangan alternatif baru dan jaringan pangan tradisional, dimana konsep aktan (istilah aktor dalam ANT) dijadikan pijakan dalam analisis. Ketiga kajian Montefrio (2020), bertujuan menggambarkan kompleksitas perkembangan sayuran Kale dalam sistem pangan di Filipina untuk mencerminkan kompleksitas pembentukan dan evolusi jaringan pangan secara transnasional dan lokal. Kajian ini menggunakan pendekatan ANT yang berfokus pada proses translation, analisis hubungan sosio-material dan assemble-thinking. Kajian keempat adalah kajian Leggett (2020) yang bertujuan menyelidiki bagaimana organisasi masyarakat sipil mengubah budaya konsumen di Cina tentang pangan hijau. Kajian ini menggabungkan konsep ontologi datar dari ANT dengan consumer culture theory.

Terakhir, sampai dengan bulan Februari tahun 2021 terdapat satu kajian yang ditemukan, yaitu kajian yang dilakukan oleh Tas Gursoy. Kajian Tas Gursoy (2021) berusaha menelusuri keterkaitan dan hubungan antara pariwisata dengan persiapan dan konsumsi roti Karakilc,ik di Turki. Kajian ini menggabungkan gagasan imajinasi sosiologi dengan konsepkonsep ANT. Konsep ANT yang digunakan dalam kajian ini cukup banyak yaitu ordering, translation, materiality dan multiplicity.

Hasil telaah keseluruhan kajian menunjukkan bahwa terdapat 2 pembahasan umum yang dibahas dalam literatur kajian sistem pangan menggunakan ANT, yaitu: 1) dinamika sistem pangan itu sendiri, dan 2) eksplorasi mengenai sebuah produk pangan. 


\section{Dinamika sistem pangan}

Studi pustaka yang dilakukan menunjukkan pembahasan dinamika sistem pangan mencoba menggali tentang: 1) Bagaimana praktik pangan tercipta dan berjalan (de Hoop \& Jehlička, 2017; Farhangi et al., 2020; Kopczyńska, 2020; Le Velly \& Dufeu, 2016; Stoddard \& Cantor, 2017; Tang et al., 2018), hampir di semua literatur kajian sistem pangan menggali hal ini untuk menjadi dasar analisis lebih lanjut; 2) Eksplorasi diskursus dan/atau ideologi dari sistem pangan (Kopczyńska, 2020; Kristensen \& Kjeldsen, 2016; Leggett, 2020; Tang et al., 2018; Taş Gürsoy, 2021); 3) Resiliensi dan keberlanjutan sistem pangan, menggali tidak hanya ketahanan namun juga kerentanan yang diciptakan dan mempengaruhi sistem pangan (Farhangi et al., 2020; Kopczyńska, 2020; Stoddard \& Cantor, 2017); 4) Eksplorasi posisi salah satu atau beberapa aktor terhadap dan/atau dalam sistem pangan (de Hoop \& Jehlička, 2017; Farhangi et al., 2020; Leggett, 2020)

Terdapat beberapa literatur yang tidak hanya menggali satu fokus pembahasan. Pertanyaan penelitian yang ditawarkan oleh literatur mendorong untuk melakukan penggalian sistem pangan dari berbagai sudut dengan menggunakan ANT. Seperti penelitian yang dilakukan oleh Kopczynska (2020) dan Leggett (2020). Kopczynska dalam penelitiannya untuk menguji potensi keberlanjutan dari jaringan pangan lokal, melakukan analisis jaringan pangan tidak hanya untuk mengetahui resiliensi dan keberlanjutan sistem pangan lokal, namun sebelumnya analisis jaringan pangan dilakukan untuk mengetahui bagaimana praktik pangan berjalan. Selain itu dengan menggunakan analisis ANT, ideologi dari sistem pangan lokal ditelaah, sehingga dapat memberikan gambaran bentuk atau cara keberlanjutan yang dilakukan oleh sistem pangan.

Berbeda dengan Kopczynska, Leggett melakukan penggalian tentang sistem pangan tanpa berfokus terlebih dahulu dengan bagaimana sistem pangan berjalan dan tercipta. Tujuan dari penelitian Leggett adalah untuk menyelidiki bagaimana sebuah aktor-organisasi masyarakat sipil - mengubah budaya konsumsi masyarakat terhadap sebuah produk pangan. Selain melakukan eksplorasi posisi aktor organisasi masyarakat sipil dalam sistem pangan, Legget juga melakukan eksplorasi diskursus yang dihadirkan oleh sistem pangan, dimana hal ini mempengaruhi tindakan aktor terhadap sistem pangan.

Beberapa konsep ANT secara khusus digunakan untuk mengeksplorasi dinamika sistem pangan. Selain itu, pembahasan dinamika sistem pangan sering kali tidak hanya menggunakan ANT sebagai alat analisisnya, namun dibantu dengan konsep atau teori lainnya. Meskipun terdapat juga literatur yang hanya menggunakan ANT sebagai satu-satunya alat analisis yang digunakan, akan tetapi jumlahnya lebih sedikit dibandingkan dengan literatur yang menggabungkan ANT dengan konsep atau teori yang lain seperti terlihat pada Tabel 1.

Tabel 1.

Fokus Pembahasan Dinamika Sistem Pangan

\begin{tabular}{|c|c|}
\hline Pembahasan Dinamika Sistem Pangan & Konsep atau Teori ANT yang Digunakan \\
\hline $\begin{array}{l}\text { Penciptaan dan mekanisme sosio-teknis } \\
\text { sistem pangan }\end{array}$ & $\begin{array}{l}\text { Hybrid Collectives, translation, enrolment, ontologi } \\
\text { datar, simetri umum, analisis aktan }\end{array}$ \\
\hline Diskursus dan ideologi sistem pangan & $\begin{array}{l}\text { Analisis aktan, translation, ontologi datar, ordering, } \\
\text { materiality, multiplicity }\end{array}$ \\
\hline Resiliensi dan keberlanjutan sistem pangan & $\begin{array}{l}\text { Konsep aktan, translation, ontologi datar, simetri } \\
\text { umum, enrolment }\end{array}$ \\
\hline Penetuan posisi aktor dalam sistem pangan & Translation, ontologi datar, simetri umum \\
\hline
\end{tabular}

Translation dan ontologi datar dari ANT merupakan alat analisis yang sering hadir dalam pembahasan dinamika sistem pangan. Translation adalah salah satu alat analisis yang penting bagi ANT. Melalui translation, aktivitas yang mendasar dari jaringan dieksplorasi, yaitu aktivitas: the assembling (perakitan), disassembling (pembongkaran), dan reassembling of associations (perakitan kembali asosiasi/himpunan), dengan mengikuti aktor manusia dan non-manusia (Baiocchi et al., 2013). Proses Translation terjadi ketika semua entitas diubah dan didaftarkan (peran dan fungsi dalam pembentukan asosiasi) agar sesuai dengan sebuah jaringan (Montefrio, 
2020). Selama proses translation, setiap aktor menerjemahkan masalah dan kepentingan aktor lain ke dalam sebuah "bahasa" dimana aktor lainnya memahaminya sehingga proses negosiasi dan konsensus terjadi. Di dalam proses ini identitas dan posisi masing-masing aktor bersifat sementara dan dapat berubah seiring dengan perubahan hubungan antar aktor, kondisi ini terus berlanjut sampai negosiasi selesai dan model jaringan disetujui dan stabil.

Dalam proses terjemahan, hubungan antara aktor manusia dan non-manusia dari sistem sosio-teknis dikonfigurasi, yang terjadi dalam 4 tahap (Farhangi et al., 2020): 1) Problematization, pada tahap ini ditentukan hambatan atau permasalahan dan tujuan jaringan yang didefinisikan oleh aktor utama serta aktor terkait lainnya; 2) Interessement, pada tahap ini negosiasi posisi para aktor terjadi dan penambahan aktor-aktor lain dilakukan untuk memperkokoh aliansi; 3) Enrolment, tahapan memperkuat dan memelihara kerjasama dengan memastikan peran dan posisi yang ditugaskan kepada mereka dalam jaringan melalui negosiasi; 4) Mobilization, tahapan dimana aktor-aktor yang terdaftar bertindak untuk memenuhi tugas yang diberikan kepada mereka.

Fungsi utama penggunaan translation adalah untuk menggambarkan pembentukan jaringan dan bagaimana mekanisme sosio-teknis dari sistem berjalan. Translation akan memberikan penjelasan kepada kita kehadiran sebuah ide atau gagasan tentang pembentukan sebuah jaringan, kemudian bagaimana usaha-usaha yang dilakukan untuk mengkooptasi para aktor sehingga jaringan dapat diwujudkan dan dikembangkan.

Kajian yang dilakukan Stoddard \& Cantor (2017) menggunakan analisis translation untuk menganalisis hubungan yang memelihara dan menstabilkan jaringan produksi daging babi di California Utara. Kajiannya menunjukkan bahwa bahasa "efisiensi" menjadi dasar dan tujuan dari jaringan, diterjemahkan kepada hubungan para aktor sehingga menciptakan sosiomekanisme yang menghadirkan aktor baru yaitu penyakit mulut dan kaki yang menyerang babi, dan menyebabkan kerentanan pada sistem produksi babi California Utara. Melalui translation, dengan banyak penekanan pada tahap enrolment, dipahami bahwa sebuah penyakit yang menyerang sebuah ekosistem sistem pangan bukan hanya tentang kondisi bio-fisik namun juga disebabkan kondisi sosio-teknis dan paradigma yang dibawa. Translation membantu kita untuk memahami hal tersebut berjalan.

Sejalan dengan kajian yang dilakukan Stoddard \& Cantor, Tang dkk (2018) dan Tas Gursoy (2021) juga memperlihatkan bagaimana sebuah paradigma mempengaruhi aktivitas sosio-teknis sistem pangan mainstream dan bagaiman paradigma sosio-teknis sistem pangan alternatif hadir menawarkan 'counter' paradigma. Translation digunakan untuk menggambarkan pendefinisian, pengaturan, dan pengalokasian dari peran, fungsi, dan kepentingan dari masingmasing aktor, sehingga menyebabkan terjadinya negosiasi dan terbangunnya konsensus. Melalui analisis translation, dapat ditelisik bahwa kehadiran jaringan pangan alternatif tidak selalu lepas dari jaringan pangan mainstream. Akan tetapi kehadiran jaringan pangan alternatif merupakan hasil hibrida dari jaringan pangan mainstream yang berkembang dengan jaringan pangan yang diharapkan (Le Velly \& Dufeu, 2016).

Proses translation tidak mengidentifikasi jaringan atau sistem berkembang secara linier dan statis. Gagasan ANT menempatkan jaringan sebagai hal yang dinamis dan dapat berubah disebabkan oleh perubahan interaksi antara aktor. Sehingga dimungkinkan terjadi transisi sosio-teknis dalam jaringan yang menghadirkan proses translation baru atau transformasi translation. Kajian yang dilakukan oleh Farhangi dkk (2020) dan Le Velly \& Dufeu (2016) membahas hal ini, dengan menggali aktor kunci yang berperan untuk melakukan transformasi, serta menggali aktor dan struktur hubungan yang menghambat, dipertahankan, dikucilkan dan dirubah di dalam jaringan.

Selain translation, ontologi datar juga merupakan konsep yang sering digunakan dalam pembahasan dinamika sistem pangan. Konsep ontologi datar beriringan dengan konsep simetri umum, dan lebih bertindak sebagai prinsip dari pendekatan ANT. Simetri umum merupakan upaya untuk menghindari pemisahan aktor manusia dan non-manusia, dengan memberlakukan objek dan subjek secara sama (Nimmo, 2011). Melalui simetri umum dipertahankan gagasan bahwa ke-aktor-an bukan karakteristik unik dan bawaan dari aktor manusia. Simetri umum adalah prinsip yang harus dijalankan agar ontologi datar dapat diterapkan. Ontologi datar 
menekankan bahwa setiap entitas adalah aktor dan jaringan pada saat yang sama, dan pendefinisian aktor dilakukan melalui hubungannya (Farhangi et al., 2020). Ontologi datar adalah salah satu dasar gagasan dari ANT yang menghindari konseptualisasi fenomena berdasarkan dikotomi biner yang memisahkan analisis alam dan sosial. Melalui ontologi datar jaringan dan aktor disifatkan sebagai entitas hibrid, gabungan dari alam, masyarakat, budaya dan teknologi, bukan entitas murni dari satu kategori (Powell, 2016). Ontologi datar juga menjadi dasar pembangunan konsep aktan dan materiality dalam ANT.

Aktan merupakan terminologi dalam ANT untuk menghindari bias penggunaan terminologi aktor yang sering diidentikkan dengan manusia. Aktan merupakan konsekuensi atau efek dari hubungan antar entitas, baik manusia maupun non manusia (Baiocchi et al., 2013). Posisi, fungsi dan identitas dari aktan bukan karakteristik yang melekat begitu saja pada aktan, akan tetapi muncul akibat interaksinya dengan aktor lain, maka dari itu sifatnya tidak statis dan dapat berubah. Melalui aktan dapat dipahami bahwa ANT merupakan manifestasi dari ontologi relasional, dimana segala hal dianggap ada karena adanya interaksi yang mengadakannya. Gagasan ini juga yang memberikan pemahaman terhadap materiality ANT, bahwa entitas material dan non-manusia memiliki peran yang sama dengan manusia dalam pembentukan jaringan/sistem (Taş Gürsoy, 2021).

Kajian sistem pangan terbantu dengan adanya pendekatan more-than human yang diberikan oleh ANT melalui simetri umum, ontologi datar, aktan dan materiality. Segala elemen dalam sistem pangan mulai dari manusia, non-manusia, alam dan sosial memiliki peran yang penting dalam sistem pangan, mulai dari hulu hingga hilir sistem pangan.

Kajian Kopczynska (2020) mengeksplorasi unsur-unsur heterogen dari sistem pangan, untuk menggambarkan lapisan-lapisan yang terdapat dalam sistem pangan dan mengidentifikasi apa yang dipertahankan, dikembangkan dan dimarginalkan di dalam jaringan. Melalui eksplorasi ini, Kopcynska dapat menganalisis potensi yang perlu dikembangkan untuk keberlanjutan sistem pangan. Sejalan dengan hal tersebut, kajian Leggett (2020) menggunakan pendekatan ontologi datar agar dapat mengeksplorasi elemen makro dan mikro dari sistem pangan, serta keterkaitan dan perubahan diantara keduanya. Hal ini dimungkinkan karena memperlakukan dunia sosial dan alam sebagai jaringan hubungan. Lapisan-lapisan - mikro dan makro - tergambarkan dengan penggalian hubungan heterogen elemen sosial dan material serta diskursus yang menyertainya. Analisis ini digunakan oleh Leggett untuk mengeksplorasi peran dan keterlibatan salah satu aktor dalam sistem pangan.

Selain konsep diatas, muncul juga konsep hybrid collectives ANT yang digunakan dalam analisis dinamika sistem pangan. ANT yang menolak paradigma biner dan dualis terhadap sebuah fenomena, menawarkan gagasan hibrid (hybrids) sebagai sifat dari jaringan, himpunan (assamblages) heterogen dimana manusia dan non-manusia bercampur tak terpisahkan (Nimmo, 2011). Sistem pangan merupakan manifestasi dari hybrid collectives, dimana berkumpulnya himpunan manusia dan non manusia, sosial dan alam. Kajian yang dilakukan Le Velly \& Dufeu (2016) menggunakan konsep hybrid collectives dengan mengidentifikasi semua aktan yang terlibat, menghasilkan penjelasan bahwa sebuah sistem pangan merupakan hibrida dari berbagai sistem pangan yang ada sebelumnya dan yang diharapkan tumbuh dalam sistem pangan baru ini. Selain itu analisis ini juga memberikan penjelasan mengapa sebuah sistem pangan berjalan tidak sesuai dengan yang diharapkan.

Pendekatan hybrid collectives juga tergambarkan dari kajian yang dilakukan oleh Tas Gursoy (2021) dengan konsep multiplicity dan ordering yang digunakannya. Konsep multiplicity digunakan oleh Tas Gursoy untuk memahami bahwa atribut yang dimiliki oleh suatu entitas merupakan kumpulan yang bercampur dari asosiasi manusia dan non manusia. Hybrid collectives tidak hanya mengacu pada sifat dari sebuah jaringan, namun juga aktor/aktan di dalam jaringan. Maka dari itu ordering (tatanan) yang terjadi juga merupakan serangkaian pengaturan dan proses yang heterogen secara material, sehingga ordering dalam sistem pangan dapat dikaitkan dengan ordering sistem lain, dimana interaksi antara ordering ini memberikan dampak pada sistem atau jaringan. Dengan menggunakan analisis ini, Tas Gursoy mengidentifikasi hubungan ekonomi, sosial, budaya, ekologi dan teknologi dari sebuah sistem pangan untuk mengeksplorasi ideologi dari sebuah sistem pangan. 


\section{Eksplorasi produk pangan}

Pembahasan umum kedua dalam kajian sistem pangan menggunakan ANT adalah eksplorasi produk pangan, pembahasan ini bertujuan untuk menggali: 1) Sejarah perubahan dan perkembangan sosio-material dari sebuah produk pangan, (Montefrio, 2020; Powell, 2016); 2) Bagaimana sebuah praktik (sosio-teknis) - seperti prosedur kontrol kualitas, penanaman, pengolahan, distribusi dll - diberlakukan kepada sebuah produk pangan (de Castro \& TorresAlbero, 2018; Taş Gürsoy, 2021).

Kajian sistem pangan yang berfokus pada penggalian sejarah perubahan dan perkembangan sosio-material dari sebuah produk, bertujuan untuk mengidentifikasi kondisikondisi yang mendorong evolusi dari sebuah produk pangan. Hal tersebut terlihat salah satunya dari kajian yang dilakukan oleh Powell (2016) dengan tujuan untuk mengeksplorasi bagaimana kondisi bio-fisik sebuah produk pangan dirubah. Dengan menggunakan ANT, Powell memusatkan perhatiannya pada proses penciptaan, pelestarian dan reproduksi produk pangan, dan bagaimana tatanan sosial memiliki andil dalam perubahan tersebut. Hasil penelitian menunjukkan bahwa perubahan produk pangan tidak hanya dipengaruhi perluasan jaringan aktor, namun juga mempengaruhi perluasan jaringan aktor tersebut.

Di samping itu, kajian yang dilakukan oleh Montefrio (2020) juga berupaya untuk menggambarkan perubahan yang dialami sebuah produk pangan. Akan tetapi fokus perubahan yang dilihat adalah perubahan identitas dan posisi produk pangan di dalam sistem pangan. Melalui analisisnya terhadap aktor dan hubungan apa saja yang mempengaruhi dan membentuk dinamika perkembangan produk pangan secara historis, Montefrio menemukan bahwa perubahan identitas dan posisi produk pangan tidak hanya didorong oleh perkembangan keterlibatan dan interaksi aktor, namun juga diskursus yang berkembang akibat dinamika interaksi jaringan pangan.

Berbeda dengan pembahasan sejarah material produk pangan, pembahasan eksplorasi praktik sosio-teknis produk pangan lebih melihat bagaimana suatu produk pangan memiliki perkembangan pada mekanisme sosio-teknis tertentu. Seperti kajian yang dilakukan oleh De Castro \& Terros-Albero (2018) yang mengeksplorasi sistem sosio-teknis dari prosedur kontrol kualitas sebuah produk pangan, dan Tas Gursoy (2021) yang mengeksplorasi praktik sosioteknis dari pembuatan dan penjualan sebuh produk pangan. Melalui penggunaan analisis ANT, kedua kajian tersebut menelusuri jaringan hubungan manusia dan non-manusia sehingga menghasilkan gambaran bentuk-bentuk sosio-teknis yang berjalan dan dipertahankan.

Terdapat literatur yang tidak hanya berfokus dalam penggalian produk pangan, namun juga terhadap sistem pangan untuk membantu memahami kondisi sosio-teknis dari sebuah produk pangan. Di samping itu, konsep ANT yang dipakai dalam pembahasan ini tidak jauh berbeda dengan pembahasan dinamika sistem pangan. Akan tetapi penggunaan ANT menjadi penggunaan utama dan dominan dalam eksplorasi produk pangan, terkhusus pada pembahasan mengenai sejarah perubahan dan perkembangan sosio-material produk pangan. Hal ini dimungkinkan karena terminologi sosio-material banyak digali dalam perkembangan ANT seperti terlihat pada Tabel 2 .

Tabel 2.

Fokus Pembahasan Eksplorasi Produk Pangan

Pembahasan Eksplorasi Produk Pangan

Sejarah sosio-material produk pangan

Praktik sosio-teknis dari produk pangan Konsep atau Teori ANT yang Digunakan Analisis sosio-material, translation, ontologi datar, aktor non-manusia

Framing-overflowing, ordering, translation, materiality, multiplicity

Sosio-material berkembang dalam kajian ANT dengan gagasannya bahwa sebuah entitas tidak hanya memiliki atribut fisik yang membangun materialnya namun juga atribut sosial. Kedua atribut ini melekat dan saling terhubung dalam entitas. ANT hadir untuk memahami keberadaan dan kehadiran atribut. Penggalian sejarah sosio-material produk pangan menggunakan ANT digambarkan dengan menganalisis hubungan timbal balik antar aktan 
disepanjang perkembangan jaringan, karena atribut merupakan hasil hubungan antar aktan. Maka dari itu sosio-material dari produk pangan juga akan berubah seiring dengan perubahan dan perkembangan hubungan para aktan. Kajian Montefrio (2020) menggunakan analisis sosiomaterial ini untuk mengeksplorasi bagaimana sebuah produk pangan memperluas dan mempersempit jaringannya, serta perubahan sosial, ekonomi, politik dan identitas biologis dari produk pangan.

Selain sosio-materil, konsep framing-overflowing ANT juga baru muncul dalam kajian sistem pangan saat membahas mengenai produk pangan. Kajian De Castro \& Torres-Albero (2018) menggunakan framing-overflowing untuk menjelaskan bagaimana prosedur sosio-teknis kontrol kualitas sebuah produk pangan berjalan. Proses ganda Framing-overflowing digunakan untuk mengambil berbagai interaksi atau proses yang membentuk konfigurasi sebuah sistem sosio-teknis Konseptualisasi framing dilakukan untuk melihat pemilihan kumpulan manusia dan non-manusia yang digunakan untuk membentuk peran dan hubungan dalam sistem sosio-teknis. Akan tetapi proses framing merupakan proses yang rapuh karena terbuka dengan "kelalaian", sehingga menghasilkan banyaknya "ketidakpastian" dalam sistem sosio-teknis, kondisi ini lah yang disebut dengan overflowing. Melalui analisis ini De Castro \& Torres-Albero mengkaji orientasi dari penciptaan dan penstabilan sistem sosio-teknis melalui asosiasi aktor manusia dan non-manusia. Melalui analisis ini pula dapat dijelaskan cara berbagai aktor mendorong proses produksi pertanian agar sesuai dengan tujuan dari prosedur sosio teknis kontrol kualitas produk.

Analisis translation juga digunakan dalam pembahasan produk pangan. Kajian Powell (2016) menempatkan produk pangan sebagai sebuah jaringan aktor, sehingga menganalisisnya menggunakan empat tahapan proses translation. Analisis translation menghasilkan gambaran bagaimana produk pangan dibangun, dilestarikan dan direproduksi. Berbeda dengan Powell, Montefrio (2020) menggunakan translation namun tidak secara utuh menerapkan tahapan translation. Fokus penggunaan analisis translation bukan kepada penciptaan dan perkembangan jaringan, namun lebih pada transformasi translation yang disebabkan adanya perubahan identitas dari produk pangan.

Sedangkan penggunaan konsep ontologi datar, materiality dan multiplicity yang digunakan dalam eksplorasi produk pangan, sama penggunaannya seperti dalam pembahasan sistem pangan. Ketiganya digunakan untuk memberikan pemahaman bahwa produk pangan harus ditempatkan sebagai aktan yang sama dengan aktan manusia, serta posisi dan indentitasnya dibentuk oleh hubungannya dengan aktan lainnya sehingga dapat berubah sesuai dengan perkembangan hubungan tersebut. Selain itu, produk pangan juga perlu dipahami sebagai produk hibrid, hasil kumpulan jaringan aktor.

\section{Perkembangan pembahasan kajian sistem pangan dengan ANT dalam Sosiologi}

Meskipun penggunaan ANT, khususnya untuk kajian sistem pangan, seringkali digunakan dalam penelitian multidisiplin, namun ANT bukanlah hal yang baru dalam Sosiologi. Bruno Latour merupakan ilmuan ANT yang memiliki latar belakang disiplin ilmu sosiologi. Latour merupakan salah satu sosiolog yang membawa ANT masuk ke dalam disiplin ilmu sosiologi. Selain Latour, terdapat juga David Goodman seorang ilmuan sosiologi pedesaan yang memberikan alternatif paradigma kajian pangan pertanian dengan menawarkan ANT sebagai pendekatan. Argumentasi dan gagasan Goodman sering dijadikan pijakan penggunaan ANT untuk kajian sistem pangan.

Ritzer (2011) mengklasifikasikan ANT sebagai salah satu pendekatan yang perlu diperhatikan oleh sosiologi di awal abad 21 karena merupakan pengembangan mutakhir dalam teori sosial kontemporer. Ritzer menyandingkan ANT dengan paradigma posthumanism dan post-sociality, serta memiliki kedekatan dengan paradigma strukturalis dan post-strukturalis. ANT memiliki potensi sebagai alat untuk mengembangkan berbagai bidang kajian di dalam disiplin ilmu sosiologi. Hasil studi pustaka yang dilakukan menemukan adanya potensi pengembangan isu kajian sistem pangan menggunakan ANT dalam disiplin ilmu sosiologi, yaitu: agensi, keadilan pangan, keamanan pangan dan gerakan (movement). 
Isu pertama agensi, merupakan salah satu konsep yang berkembang dalam teori sosiologi, seperti dalam teori strukturasi yang dikembangkan oleh Anthony Gidden dan konsep habitus-field yang dikembangkan oleh Pierre Bourdieu. Penggalian agensi menggunakan ANT akan memberikan pendekatan yang berbeda dengan teori sosiologi mengenai agensi yang sudah ada sebelumnya. Perbedaan yang paling mencolok adalah dimungkinkannya entitas nonmanusia memiliki agensi. Penekanan pada ontologi relasional dan penolakan terhadap kerangka berpikir yang dualis dari ANT, memberikan peluang entitas non-manusia untuk memiliki agensi seperti manusia. Kajian sistem pangan yang dilakukan oleh Le Velly \& Dufeu (2016), Stoddard \& Cantor (2017) dan Farhangi dkk (2020) menunjukkan bahwa pembahasan mengenai agensi mungkin dilakukan oleh ANT dan memiliki manfaat untuk kajian sistem pangan.

Agensi sebagai kemampuan untuk bertindak dihasilkan dari asosiasi yang dibangun oleh entitas manusia dan non-manusia. Kajian yang dilakukan oleh Le Velly \& Dufeu (2016) memberikan gambaran bahwa agensi - kemampuan bertindak - yang hadir dalam sebuah entitas, baik manusia dan non-manusia, merupakan sebuah hasil hybrid collectives. Hal ini akan memberikan pemahaman aktor apa saja dan hubungan seperti apa yang akan menghadirkan sebuah agensi pada aktor dalam sebuah jaringan. Sejalan dengan Le Velly \& Dufeu, kajian yang dilakukan Stoddard \& Cantor (2017) memberikan gambaran bagaimana sebuah hubungan dari beberapa aktor memicu keagenan aktor lain. Disebabkan agensi bersifat relasional, agensi aktor dapat dipicu oleh aktivitas-aktivitas relasional dari aktor lain. Pada kajian Stoddard \& Cantor, aktor yang selama ini tidak ada, tiba-tiba hadir disebabkan aktivitas relasional aktor lain, dan memberikan "guncangan" pada jaringan. Sedangkan penggalian agensi yang dilakukan Farhangi dkk (2020) lebih mutakhir. Usaha Farhangi dkk berusaha menganalisis agensi secara lebih terukur dalam upayanya untuk mempelajari peran aktor manusia dan non-manusia pada sebuah sistem sosio-teknis. Keagenan setiap aktor diukur dengan menganalisis hubungan antar aktor yang terlibat melalui tiga indeks, yaitu banyaknya ikatan aktor dengan aktor lainnya (derajat sentralitas), posisi aktor dengan pasang aktor lainnya (betweenness), dan kemampuan aktor menjangkau aktor lainnya (closeness). Analisis ini memberikan gambaran peran dari aktor dan aktor mana yang menjadi kunci dalam jaringan.

Isu kedua dan ketiga, keadilan dan keamanan pangan merupakan isu yang menjadi objek kajian sosiologi. Pada sosiologi pangan dan pertanian, kedua isu ini banyak dibahas dan dikembangkan. Kajian sistem pangan dengan menggunakan ANT memberikan analisis dengan sudut pandang yang berbeda untuk menggali keadilan dan keamanan pangan. Kajian yang dilakukan oleh Tas Gursoy (2021) menggunakan pendekatan ANT untuk mengeksplorasi hubungan sosio-teknis dari sistem pangan dengan ekonomi, budaya, lingkungan dan teknologi. Eksplorasi hubungan ini digunakan oleh Tas Gursoy untuk mengidentifikasi siapa saja yang sebenarnya diuntungkan dan dirugikan dalam sistem pangan. Pembahasan lebih jauh adalah untuk menggambarkan sejauh mana keadilan pangan dihasilkan oleh sebuah sistem pangan dengan ideologi tertentu.

Selanjutnya pembahasan mengenai keamanan pangan dieksplorasi oleh kajian Stoddard \& Cantor (2017). Melalui penggunaan konsep keagenan ANT dan translation, Stoddard \& Cantor menggali hubungan para aktor yang memicu kehadiran aktor lainnya yang berbahaya bagi keamanan pangan. Entitas yang membahayakan keamanan pangan dilihat sebagai entitas relasional yang kehadirannya merupakan hasil hubungan aktor dalam jaringan. Penggunaan ANT dalam kasus ini memberikan kemudahan untuk mengidentifikasi aktivitas-aktivitas relasional yang berpotensi membahayakan keamanan pangan dalam sistem pangan, serta ideologi atau paradigma yang mendasarinya.

Isu terakhir adalah gerakan, fokus pembahasannya telah dibahas secara luas oleh sosiologi dan telah memiliki beberapa teori ajek. Pembahasan diskursus dan ideologi sistem pangan membawa kepada eksplorasi gerakan yang terjadi dalam dunia pangan. Salah satu diantaranya adalah kajian Leggett (2020) yang bertujuan mengidentifikasi upaya-upaya organisasi masyarakat sipil mengubah budaya konsumsi masyarakat. Analisis menggunakan pendekatan ANT dilakukan untuk mengidentifikasi interaksi-interaksi yang dilakukan oleh organisasi masyarakat sipil dan proses perubahan yang terjadi. ANT memungkinkan penggalian tidak pada level mikro dari gerakan namun juga makro. Hasilnya adalah eksplorasi lapisan- 
lapisan perakitan kumpulan dan perluasan hubungan antara elemen sosial, material dan diskursus dalam perkembangan gerakan.

\section{Simpulan dan Saran}

Studi pustaka menunjukkan penggunaan ANT dalam kajian sistem pangan selama lima tahun terakhir dapat dikerucutkan menjadi dua fokus pembahasan yaitu dinamika sistem pangan dan eksplorasi produk pangan. Kedua pembahasan ini memiliki tujuan penggalian yang berbeda-beda. Proses translation merupakan konsep yang paling sering digunakan dalam kajian sistem pangan, karena dapat menggambarkan terciptanya dan berjalannya sistem pangan. Selain itu penggunaan ANT dalam kajian sistem pangan memiliki banyak potensi pengembangan yang dapat dieksplorasi seperti konsep agensi dari sosiologi, isu keadilan pangan, keamanan pangan dan gerakan sosial dalam dunia pangan. ANT memberikan kesempatan pada kajian sistem pangan untuk menghadirkan entitas non-manusia yang lebih aktif, partisipatif dan memiliki signifikasi dalam dinamika sistem pangan. Selain itu, pendekatan jaringan aktor dari ANT yang berbeda dengan pendektaan jaringan lainnya, telah mendorong perubahan analisis sosiologis, yang selama ini dualistis, dilebur menjadi "assembly association" yang bersifat hybrid. Para peneliti sosial dan sistem pangan khususnya perlu melakukan penelitian lebih lanjut yang menggali penggunaan ANT untuk potensi isu yang lebih luas dalam kajian sistem pangan. Hal ini penting untuk dapat menguji sejauhmana ANT dapat digunakan untuk menjawab pertanyaan dan permasalah yang lebih asbtrak seperti keamana pangan dan keadilan pangan. Selain itu, penelitian yang lebih sering menggunakan ANT juga dapat mengembangkan konsep-konsep ANT sehingga menghasilkan kekayaan analisis, dan akhirnya dapat mendorong penggunaan ANT ke ranah-ranah yang belum pernah dikajianya.

\section{Ucapan Terimakasih}

Saya ingin mengucapkan terima kasih sebesar-besarnya kepada Dr. Johannes Prio Sambodho, M.P.P yang telah bersedia berdiskusi mengenai gagasan yang coba saya bawa dalam studi literatur ini.

\section{Daftar Rujukan}

Baiocchi, G., Graizbord, D., \& Rodríguez-Muñiz, M. (2013). Actor-Network Theory and the ethnographic imagination: An exercise in translation. Qualitative Sociology, 36(4), 323-341. https://doi.org/10.1007/s11133-013-9261-9

Bernstein, H. (2016). Agrarian political economy and modern world capitalism: the contributions of food regime analysis. Journal of Peasant Studies, 43(3), 611-647. https://doi.org/10.1080/03066150.2015.1101456

Bui, S., Costa, I., De Schutter, O., Dedeurwaerdere, T., Hudon, M., \& Feyereisen, M. (2019). Systemic ethics and inclusive governance: two key prerequisites for sustainability transitions of agri-food systems. Agriculture and Human Values, 36(2), 277-288. https://doi.org/10.1007/s10460-019-09917-2

Carolan, M. (2012). The Sociology of Food and Agriculture. Routledge. https://doi.org/10.4135/9781412939645.n79

Challies, E. (2012). The Limits to Voluntary Private Social Standards in Global Agri-food System Governance. International Journal of Sociology of Agriculture and Food, 20(2), 175-195.

de Castro, C., \& Torres-Albero, C. (2018). Designer Grapes: The Socio-Technical Construction of the Seedless Table Grapes. A Case Study of Quality Control. Sociologia Ruralis, 58(2), 453469. https://doi.org/10.1111/soru.12186

de Hoop, E., \& Jehlička, P. (2017). Reluctant pioneers in the European periphery? Environmental activism, food consumption and "growing your own." Local Environment, 22(7), 809-824. https://doi.org/10.1080/13549839.2017.1289160

Dixon, J., \& Richards, C. (2016). On food security and alternative food networks: understanding and performing food security in the context of urban bias. Agriculture and Human Values, 33(1), 191-202. https://doi.org/10.1007/s10460-015-9630-y

Duncan, J., \& Pascucci, S. (2017). Mapping the Organisational Forms of Networks of Alternative 
Food Networks: Implications for Transition. Sociologia Ruralis, 57(3), 316-339. https://doi.org/10.1111/soru.12167

Dwiartama, A. (2014). Investigating resilience of agriculture and food systems: Insights from two theories and two case studies. University of Otago.

Dwiartama, A., \& Rosin, C. (2014). Exploring agency beyond humans: The compatibility of ActorNetwork Theory (ANT) and resilience thinking. Ecology and Society, 19(3). https://doi.org/10.5751/ES-06805-190328

Farahzad, F., \& Varmazyari, H. (2018). Translators' identities within approaches to translation sociology: A comparative study of trainee translators. InTRAlinea, 20(July 2018).

Farhangi, M. H., Turvani, M. E., van der Valk, A., \& Carsjens, G. J. (2020). High-tech urban agriculture in Amsterdam: An actor network analysis. In Sustainability (Switzerland) (Vol. 12, Issue 10). https://doi.org/10.3390/SU12103955

Fox, N. J., \& Alldred, P. (2018). Social structures, power and resistance in monist sociology: (New) materialist insights. Journal of Sociology, 54(3), 315-330. https://doi.org/10.1177/1440783317730615

Jenatton, M., \& Morales, H. (2020). Civilized cola and peasant pozol: young people's social representations of a traditional maize beverage and soft drinks within food systems of Chiapas, Mexico. Agroecology and Sustainable Food Systems, 44(8), 1052-1088. https://doi.org/10.1080/21683565.2019.1631935

Kopczyńska, E. (2020). Are there local versions of sustainability? Food networks in the semiperiphery. Sustainability (Switzerland), 12(7). https://doi.org/10.3390/su12072845

Kristensen, D. K., \& Kjeldsen, C. (2016). Imagining and doing agro-food futures otherwise: Exploring the Pig City experiment in the foodscape of Denmark. Journal of Rural Studies, 43, 40-48. https://doi.org/10.1016/j.jrurstud.2015.11.011

Lamine, C. (2015). Sustainability and resilience in agrifood systems: Reconnecting agriculture, food and the environment. Sociologia Ruralis, 55(1), 41-61. https://doi.org/10.1111/soru.12061

Le Velly, R., \& Dufeu, I. (2016). Alternative food networks as "market agencements": Exploring their multiple hybridities. Journal of Rural Studies, 43, 173-182. https://doi.org/10.1016/j.jrurstud.2015.11.015

Leblond, N., \& Trottier, J. (2016). Performing an invisibility spell: Global models, food regimes and smallholders. International Journal of Sociology of Agriculture \& Food, 23(1), 21-40.

Leggett, A. (2020). Bringing green food to the Chinese table: How civil society actors are changing consumer culture in China. Journal of Consumer Culture, 20(1), 83-101. https://doi.org/10.1177/1469540517729009

Mak, S. W. (2014). The Revival of Traditional Water Buffalo Cheese Consumption: Class, Heritage and Modernity in Contemporary China. Food and Foodways, 22(4), 322-347. https://doi.org/10.1080/07409710.2014.973797

Montefrio, M. J. F. (2020). The 'queen of greens' comes to the tropics: (De)Territorialization of kale's socio-material relations in the Philippines. Geoforum, 116(January), 24-32. https://doi.org/10.1016/j.geoforum.2020.07.015

Nimmo, R. (2011). Actor-Network Theory and Methodology: Social Research in a More-ThanHuman World. Methodological Innovations Online, 6(3), 108-119. https://doi.org/10.4256/mio.2011.010

Plumecocq, G., Debril, T., Duru, M., Magrini, M. B., Sarthou, J. P., \& Therond, O. (2018). The plurality of values in sustainable agriculture models: Diverse lock-in and coevolution patterns. Ecology and Society, 23(1). https://doi.org/10.5751/ES-09881-230121

Powell, J. B. (2016). White Maize to Pigarro: An Actor-Network Analysis of an Improved Crop Variety in Northwest Portugal. Journal of Ethnobiology, 36(1), 45-65. https://doi.org/10.2993/0278-0771-36.1.45

Ritzer, G. (2011). Sociological Theory (8th ed.). McGraw-Hill. https://doi.org/10.2307/j.ctt1t892z5.19

Stoddard, E. A., \& Cantor, A. (2017). A Relational Network Vulnerability Assessment of the North Carolina Hog Industry. Annals of the American Association of Geographers, 107(3), 682-699. 
https://doi.org/10.1080/24694452.2016.1261679

Tang, J. W., Chen, M. L., \& Chiu, T. H. (2018). An exploratory study on local brand value development for Outlying Island Agriculture: Local food system and actor-network theory perspectives. Sustainability (Switzerland), 10(11). https://doi.org/10.3390/su10114186

Taş-Gürsoy, İ. (2021). Slow food justice and tourism: tracing Karakllçık bread in Seferihisar, Turkey. Journal of Sustainable Tourism, 29(2-3), 466-486. https://doi.org/10.1080/09669582.2020.1770772

Tilzey, M. (2019). Food Regimes, Capital, State, and Class: Friedmann and McMichael Revisited. Sociologia Ruralis, 59(2), 230-254. https://doi.org/10.1111/soru.12237

Williams, I. (2020). Contemporary Applications of Actor Network Theory. In Idongesit Williams (Ed.), Palgrave Macmillan. Springer Nature Singapore Pte. Ltd. https://doi.org/10.1007/978-981-15-7066-7 